\title{
Blogs de adolescentes surdos: escrita e construção de sentido
}

\author{
Cláudia Alquati Bisol \\ Eduardo Scarantti Bremm \\ Carla Beatris Valentini
}

\section{Resumo}

A aprendizagem e a apropriação significativa da língua escrita por surdos podem ser promovidas por meio da utilização de tecnologias de comunicação amplamente difundidas. Este trabalho apresenta a análise dos recursos narrativos utilizados por três adolescentes surdos fluentes em LIBRAS para organizar sua experiência vivida através de produções escritas em weblogs (utilizando a língua portuguesa, sua segunda língua). Trata-se de um estudo qualitativo, do tipo exploratório. Propôs-se uma análise hermenêutica das narrativas baseada em Paul Ricoeur. Apesar dos erros na escrita, as produções puderam ser consideradas como narrativas, pois exprimem tentativas de tecer histórias. Porém, nem sempre a transmissão do sentido foi bem sucedida, indicando dificuldades na aprendizagem da língua escrita e na compreensão de que esta pode ser um meio de comunicação com o outro. Ressalta-se a necessidade de se criar estratégias que reforcem a noção da língua escrita como meio de produção de sentido.

Palavras-chave: Adolescentes, surdo, comunicação e tecnologia.

\section{Deaf adolescents' blogs: writing and construction of meaning}

\begin{abstract}
The learning and the meaningful appropriation of the written language by the deaf can be promoted by means of the use of widely spread and available communication technologies. This work presents the analysis of the narrative resources used by three deaf adolescents fluent in Libras to organize their lived experience through written productions in weblogs (using the Portuguese language, their second language). It is a qualitative exploratory study. A hermeneutic analysis of the narratives based on Paul Ricoeur was proposed. Although there were mistakes in the written language, the productions could be considered narratives because they express attempts to weave stories. However, the transmission of meaning was not always successful, indicating difficulties in the learning of the written language and in the understanding that it can be a means of communicating with the other. The need of creating strategies that strengthen the notion of the written language as a means of production of meaning is emphasized.
\end{abstract}

Keywords: Adolescents, deaf, communication and technology.

\section{Blogs de adolescentes sordos: escritura y construcción de sentido}

\section{Resumen}

El aprendizaje y la apropiación significativa de la lengua escrita por sordos pueden ser promovidas por medio de la utilización de tecnologías de comunicación ampliamente difundidas. Este trabajo presenta el análisis de los recursos narrativos utilizados por tres adolescentes sordos fluentes en Libras (Lengua Brasileña de Señales) para organizar su experiencia vivida a través de producciones escritas en weblogs (utilizando la lengua portuguesa, su segunda lengua). Se trata de un estudio cualitativo, de tipo exploratorio. Se propuso un análisis hermenéutico de las narrativas con base en Paul Ricoeur. A pesar de los errores en la escritura, fue posible considerar las producciones como narrativas, pues exprimen intentos de tejer historias. Sin embargo, no siempre la transmisión del sentido fue exitosa, indicando dificultades en el aprendizaje de la lengua escrita y en la comprensión de que ésta puede ser un medio de comunicación con el otro. Se resalta la necesidad de crearse estrategias que refuercen la noción de la lengua escrita como medio de producción de sentido.

Palabras-clave: Adolescentes, sordo, comunicación e tecnología. 


\section{Introdução}

A lei $n^{\circ}$ 10.436, de 24 de abril de 2002, dispõe sobre o reconhecimento da Língua Brasileira de Sinais (LIBRAS) como forma de comunicação e expressão das comunidades de pessoas surdas do país. A aprovação desta lei foi um importante passo na luta pela conquista de uma série de direitos dos surdos, como a disponibilização de intérpretes em serviços públicos, ensino de LIBRAS e atendimento e tratamento adequado em LIBRAS.

No entanto, a língua portuguesa escrita continua sendo um importante meio de comunicação e informação para o surdo, pois amplia a possibilidade de negociação de sentidos e acesso a um conhecimento de grande amplitude. Sabe-se, porém, que a aprendizagem da língua escrita pela criança surda é um processo extremamente complexo (Capovilla \& Capovilla, 2002).

O presente trabalho tem por objetivo discutir a escrita em língua portuguesa de adolescentes surdos em weblogs. O foco não está colocado sobre a análise da ortografia, gramática ou sintaxe, mas sim na produção e negociação de sentido, enfatizando os elementos da narrativa como a temporalidade, os personagens, as circunstâncias e as ações, as mediações simbólicas e as interações entre o autor e seu leitor. Portanto, compreende-se o uso do português escrito enquanto meio de produção e transmissão de sentido através das narrativas criadas nos blogs. Partindo dessa compreensão narrativa, esse trabalho visa investigar os recursos narrativos utilizados por adolescentes surdos fluentes em LIBRAS para organizar a experiência vivida em língua portuguesa através de produções escritas em blogs. Com isso, pretende-se apresentar uma via interessante para trabalhar com estudantes surdos em sala de aula, com fins de aprendizagem e apropriação ativa e significativa da língua portuguesa escrita, mas também como um meio de promover a inclusão dos jovens surdos no universo digital e no uso das tecnologias da comunicação para a construção de redes de interação.

\section{Língua de sinais e língua escrita}

As línguas de sinais são línguas naturais que possuem sistemas semióticos, gramática, morfologia e léxico próprios. Nörth (1990) analisa a independência das línguas de sinais em relação às línguas faladas/escritas a partir de três aspectos de autonomia: a) autonomia estrutural: as línguas de sinais não são um soletramento ou tradução das palavras, são sinais caracterizados por um alto grau de iconicidade e de independência em relação a outros tipos de representações; b) autonomia geográfica: as línguas de sinais têm limites territoriais próprios, existe um grau de mutabilidade dos sinais de uma região para outra; e c) autonomia funcional: existem diferentes circunstâncias de uso e disponibilidade das línguas de sinais, já que privilegiam o canal visual em vez do auditivo. O caráter espontâneo da comunicação em sinais e a preferência dos surdos em se comunicar através da via visual levam diversos autores a considerar as línguas de sinais como naturais do sujeito surdo (Capovilla \& Capovilla, 2002; Silva, 1999).

Nos últimos anos, têm-se estudado possibilidades de convencionar uma escrita que registre as línguas de sinais. O sistema mais utilizado é o Sign Writing ${ }^{\circledR}$, criado em 1974 por Valerie Sutton, que consiste na utilização de símbolos visuais para a escrita de diferentes línguas de sinais através de um sistema de representação gráfica. Uma possibilidade de adaptação da LIBRAS para esse sistema tem sido proposta por Stumpf $(2000,2005)$. No entanto, reconhecer a importância da língua escrita de sinais não diminui a relevância da leitura e escrita da língua majoritária do país, pois esta amplia as possibilidades de comunicação, negociação de sentidos e acesso ao conhecimento social e cultural de grande circulação (Arcoverde, 2006; Rodda \& Eleweke, 2000).

Que desafios enfrentam as crianças surdas para o aprendizado da língua escrita? O domínio da leitura e da escrita da língua portuguesa nem sempre é fácil para o surdo. O meio sociocultural, o ambiente familiar, a etiologia e a idade na qual ocorre a perda auditiva, a precocidade do diagnóstico, o acesso a serviços de saúde especializados e as possibilidades educacionais são alguns fatores importantes que influenciam no desenvolvimento afetivo e escolar da criança surda. Deve-se considerar os fatores específicos de cada criança e de cada situação que interferem em suas condições para o aprender (Virole, 2001, 2003). Além disso, há especificidades nas línguas de sinais que influenciam na aprendizagem da língua escrita. Em diversas línguas orais, a escrita alfabética mapeia os sons da língua falada, firmando a relação entre os sons e a palavra. Ou seja, a escrita opera uma codificação fonológica, transcrevendo o processo de informação da língua falada. A fala é uma representação primária que serve de base para a escrita e leitura, que são representações secundárias (Capovilla \& Capovilla, 2002). Para a criança surda, as representações primárias não são registradas pela fala, mas pelos sinais. Falta este registro sonoro que auxilia na aprendizagem da escrita (Capovilla \& Capovilla, 2002). Por isso, o encontro entre a criança surda e o texto consiste num duplo desafio: internalizar aspectos da língua oral e aprender as técnicas envolvidas na representação do código linguístico (Webster \& Heineman-Gosschalk, 2000).

Surdos tendem a escrever frases isoladas em português e tendem a apresentar algumas singularidades no texto, como fazer pouco uso de pontuação (Meirelles \& Spinillo, 2004). Góes (1996) refere-se também ao uso inadequado e à omissão de preposições, erros na conjugação e no tempo verbal gerando inconsistências entre passado e presente, flexão inadequada de gênero (adjetivos, artigos), uso incorreto ou ambíguo de pronomes pessoais e possessivos e de elos coesivos, inclusão de palavras inventadas com significados não convencionais e ausência de conexão entre as partes do texto. Segundo Guarinello, Massi e Berberian (2007), esses aspectos são de certa forma explicados pela sintaxe da LIBRAS não utilizar conectivos, tempo verbal e preposições. Apesar dessas especificidades, os elementos narrativos uti- 
lizados pelos surdos para dar coerência a uma narrativa são suficientes para transmissão de sentido, ou seja, as dificuldades e as especificidades de sua escrita não são obstáculo à construção da narrativa (Bisol, 2008; Silva, 2000).

Stumpf (2000) afirma que a produção escrita dos surdos é quase inexistente, limitando-se a comunicações rudimentares feitas com dificuldade; na leitura, a compreensão é pequena mesmo após anos de escolarização. Além de todas essas considerações, é importante lembrar que as práticas pedagógicas também fracassam em relação aos ouvintes. Nesse sentido, os surdos enfrentariam demandas adicionais (Góes, 1996).

Diferentes abordagens na educação dos surdos são utilizadas para o ensino da leitura e escrita: Oralismo, Comunicação Total e Bilinguismo. O Bilinguismo tem sido a abordagem mais aceita e utilizada atualmente, contudo, segundo Guarinello e cols. (2007), em muitas das escolas especiais bilíngues ocorrem dificuldades na implantação dessa abordagem. Professores tendem a não dominar fluentemente a língua de sinais e a utilizar uma forma de comunicação ambígua que implica numa compreensão limitada do conteúdo. Outro problema identificado por Almeida (2002/2003) é que a ênfase da aprendizagem da leitura dá-se na palavra (aprendizagem de vocábulos, memorização de palavras, decodificação ou codificação) e não no sentido que ela visa transmitir. Ao adotar práticas educacionais que focalizam o vocábulo isolado, "a escola leva os alunos a prestarem atenção às palavras individualmente, preocupando-se em entender o significado literal das palavras e não buscando um sentido mais amplo" (Pereira \& Karnopp, 2003, p. 167).

\section{Recursos midiáticos para o desenvolvimento da escrita}

São inegáveis as mudanças que as novas tecnologias têm proporcionado à vida de surdos e ouvintes. No filme Babel (Iñárritu \& Arriaga, 2006), é possível observar a personagem Cheiko Wataya, uma adolescente surda japonesa fluente em língua de sinais que utiliza diferentes recursos tecnológicos para se comunicar à distância com seu pai ouvinte e com suas amigas surdas, Cheiko utiliza o sistema SMS de celular e a transmissão instantânea de vídeos que permite a comunicação em língua de sinais. Outros recursos utilizados por Cheiko são o sistema closed caption de televisão e sinalizadores visuais que substituem os sinais sonoros na campainha da porta ou no alerta do forno de microondas.

Dentre os novos recursos tecnológicos, a internet se constituiu em um importante campo de interação e compartilhamento de informações. Os recursos disponíveis são inúmeros: webcams, weblogs, vlogs, softwares de comunicação oral através da internet, programas de mensagens instantâneas, correio eletrônico, acesso a sites, chats e serviços de rede social onde os usuários podem interagir e compartilhar fotos e perfis e participar de comunidades virtuais. Para os surdos, a internet pode trazer uma série de benefícios, como o aumento de interações entre membros da comunidade surda independente da distância geográfica, a aprendizagem e o uso da língua de sinais escrita, o conhecimento da cultura da informática e o acesso à história e à cultura surda (Stumpf, 2000). Recursos como compartilhamento de vídeos on-line permitem ainda que a comunicação se dê diretamente em língua de sinais.

As novas tecnologias também podem ser utilizadas no processo de aprendizagem da escrita em língua portuguesa. A utilização do computador como ferramenta auxiliar no processo de ensino e aprendizagem possibilita que o aluno vivencie situações que facilitam o desenvolvimento de suas potencialidades de maneira lúdica. Um amplo estudo sobre leitura e escrita foi realizado por Toscano, McKee e Lepoutre (2002) com estudantes surdos bem sucedidos nessas áreas. A maioria afirmou que teve acesso a computadores quando criança, utilizando-os também como meio para manter contato com amigos e família e sentir-se mais próximo deles. $\mathrm{O}$ uso do computador parece ter permitido a esses estudantes oportunidades adicionais de exercitar a leitura e a escrita em contextos motivadores de interação. Henderson-Summet, Grinter, Carroll e Starner (2007) também observaram que a utilização dos recursos tecnológicos para comunicação, por adolescentes surdos, permite o uso da língua escrita de modo informal, havendo maior preocupação em se comunicar do que em escrever corretamente.

O weblog, também conhecido como blog ou diário virtual, permite aos usuários colocar conteúdo na rede e interagir com outros usuários. Essa ferramenta apresenta as vantagens de ser facilmente criada, editada e publicada, sem exigir conhecimentos técnicos especializados. O blog é um tipo de publicação online com estrutura hipertextual, caracterizado por textos curtos e postados em blocos padronizados (posts), organizados em ordem cronológica reversa. Cada bloco de texto gera um link permanente de acesso que pode ser enriquecido por comentários intertextuais e interdependentes (Gutierrez, 2003, 2005). Essa possibilidade de comentar os posts em outros blogs permite a interação com o leitor, gerando redes sociais abertas em constante construção, que Gutierrez (2003) denomina "blogosfera".

Além disso, o weblog possibilita um espaço para a emergência da autoria, pois permite ao blogueiro narrar a si mesmo e acessar seus sentimentos e percepções. O blogueiro também pode transformar os aspectos visuais desse ambiente virtual, enfatizando o caráter estético e estrutural da página (Gutierrez, 2005). Uma experiência com o uso de blogs por adolescentes surdos foi realizada por Camargo, Valentini e Bisol (2005). Os jovens mostraram facilidade de se apropriar das ferramentas disponibilizadas em ambientes informatizados e curiosidade em conhecer as opções de ferramentas disponíveis para formatação de posts e interface do blog.

\section{Narrativa}

Alguns estudos têm procurado entender os processos de construção identitária de pessoas surdas a partir do estu- 
do de narrativas sinalizadas em uma perspectiva de análise hermenêutica (Breivik, 2005; Bremm \& Bisol, 2008; Ohna, 2004). Pequenas narrativas escritas por jovens surdos foram analisadas por Bisol (2008). A autora observou que, apesar das dificuldades de utilizar o português escrito, os surdos utilizaram elementos narrativos suficientes para construir sentido. No presente artigo, as produções escritas dos weblogs também foram analisadas sob o ponto de vista das narrativas tomando por base a hermenêutica de Ricoeur.

A filosofia hermenêutica de Paul Ricoeur traz avanços aos estudos da narrativa. Enfatiza que o exame de uma vida se dá pela operação de contá-la. A narrativa é compreendida como uma configuração que liga uma série de acontecimentos, criando uma totalidade significante (Ricoeur, 1994). A intriga configura os acontecimentos em uma história, compondo fatores heterogêneos como circunstâncias, personagens, interações e causalidades. Na narrativa autobiográfica, o autor corresponde ao narrador e é, ao mesmo tempo, personagem da própria história. Dessa maneira, o autor-narradorpersonagem de uma autobiografia pode construir diversas versões sobre si mesmo e ressignificar sua existência.

A narrativa "imita" a ação humana no sentido de que produz uma representação por meio da linguagem, ao que Ricoeur (1994), apoiando-se em Aristóteles (no livro A Poética), chama de mimese. A narrativa tem a capacidade de reconfigurar a realidade prática, da experiência e do vivido, na medida em que o texto tende a abrir intencionalmente o horizonte a uma realidade nova, o mundo do texto. Como afirma Ricoeur (1997, p. 197), "este mundo do texto intervém no mundo da ação para configurá-lo ou, me atreveria a dizer, para transfigurá-lo".

A tese básica de Ricoeur $(1994,1997)$ é de que o caráter comum da experiência humana, articulado pelo ato de narrar em todas suas formas, é seu aspecto temporal. Tudo o que se conta sucede no tempo, se desenvolve temporalmente, e o que se desenvolve no tempo pode ser narrado. A mediação entre tempo e narrativa é constituída através da relação entre três modos miméticos. Os três níveis da operação mimética (mimeses I, II e III) propostos por Ricoeur (1994) constituem o ato de narrar e a própria experiência compreensiva.

O tempo prefigurado da narrativa denomina-se mimese I. A composição da intriga está enraizada numa précompreensão do mundo e da ação, alicerçada no universo simbólico da cultura. $\mathrm{O}$ ato de narrar depende de um sistema simbólico que forneça um contexto de descrição da ação: "Se, com efeito, a ação pode ser narrada, é porque ela já está articulada em signos, regras, normas: é, desde sempre, simbolicamente mediatizada" (Ricoeur, 1994, p. 91, grifo do autor).

O segundo momento da operação narrativa (mimese II) constitui-se na tessitura da intriga. É o momento da configuração do texto propriamente dito, no qual a experiência será modelada através da intriga pela transformação de uma simples sucessão de eventos em uma totalidade significante. A mimese III, último tempo da operação mimética, consiste na intersecção do mundo do texto com o mundo do ouvinte ou do leitor. O tempo é refigurado na medida em que alguém lê ou ouve a narrativa. "É no ouvinte ou no leitor que se conclui o percurso da mimese" (Ricoeur, 1994, p. 110).

\section{Método}

Este trabalho delineia-se como uma pesquisa qualitativa do tipo exploratório (Richardson, 1999). Os dados provêm de um projeto que promoveu a produção de textos em weblogs por adolescentes surdos para criação de narrativas, tomando-as como instrumentos facilitadores para a construção e compartilhamento de sociobiografias (Camargo e cols., 2005). Neste projeto, desenvolvido em parceria com uma escola especial para surdos, foram desenvolvidas atividades com as turmas de $6^{a}$ e $7^{a}$ séries do Ensino Fundamental, nas quais participaram 11 adolescentes surdos sinalizadores fluentes em LIBRAS com idades variando entre 13 e 18 anos. As atividades foram feitas em horário de aula, com autorização da direção da escola e dos pais dos alunos e com acompanhamento de uma professora e da psicóloga da escola. Os estudantes utilizaram o laboratório de informática da universidade ou da escola para produzir weblogs que enfocavam narrativas de suas experiências de vida e, posteriormente, ler e comentar os weblogs dos colegas. Utilizou-se um serviço gratuito de edição e hospedagem de weblogs disponível na internet que facilitava a postagem e a edição do layout das páginas. Para o presente trabalho, foram escolhidas as produções de três participantes do grupo de 11 alunos que, uma vez publicadas na internet, estavam disponíveis para acesso público.

A Participante 1 tem 13 anos, frequenta a $6^{a}$ série do Ensino Fundamental, teve a surdez diagnosticada quando tinha um ano e dois meses. Com um ano e onze meses, ingressou em uma escola especial para surdos. O Participante 2 tem 17 anos, frequenta a $7^{a}$ série do Ensino Fundamental, sua surdez foi diagnosticada aos dois anos, sendo que, com quatro anos e seis meses, ele foi matriculado em uma escola especial para surdos. O participante 3 tem 14 anos e frequenta a $6^{\mathrm{a}}$ série do Ensino Fundamental. A surdez foi diagnosticada com cerca de três anos e logo passou a frequentar uma escola especial para surdos. Todos os participantes fizeram acompanhamento fonoaudiológico e apenas o Participante 3 faz uso regular de prótese auditiva. Os dados sobre a história de vida desses três participantes foram obtidos em projeto simultâneo (Bremm \& Bisol, 2008) e foram utilizados para complementar a discussão dos resultados do presente trabalho.

\section{Análise dos dados}

A análise aqui desenvolvida baseou-se na proposta de Bisol (2008) para análise de pequenas narrativas escritas e em trabalho anterior desenvolvido por Bremm e Bisol (2008). Os três tempos da mimese (Ricoeur, 1994) serviram de base para a construção de um quadro de análise das narrativas apresentado na Tabela 1 . Os elementos narrativos 
Tabela 1. Quadro de Análise

\begin{tabular}{lll}
\hline & Elementos de Análise & Etapa de Análise \\
\hline Mimese II & Tema & Primeira \\
& Marcadores temporais & \\
\cline { 2 - 3 } & Personagens, interações e ações & Segunda \\
Mimeses I e III & Circunstâncias & \\
\cline { 2 - 3 } & Mediações simbólicas & Terceira \\
& Relação entre narrador e leitor & \\
\hline
\end{tabular}

Fonte: Elaboração dos autores.

identificados em cada produção escrita foram organizados a partir desse quadro de análise:

Na primeira etapa, a análise do tema e dos marcadores temporais permitiu identificar as produções escritas que poderiam ser compreendidas como narrativas. Na segunda etapa, em cada narrativa foram identificados os personagens, suas interações, as ações e as circunstâncias. $\mathrm{Na}$ terceira etapa, foram identificadas as mediações simbólicas (regras, normas, julgamentos) e os elementos da relação entre narrador e leitor.

Os nomes de cidades, pessoas e locais foram alterados para garantir o sigilo na apresentação dos resultados. Manteve-se a grafia original das produções, tal como foram escritas.

\section{Resultados}

A primeira etapa de análise consistiu em identificar se as produções escritas poderiam ser consideradas narrativas através da análise do tema da narrativa e dos marcadores temporais. Baseando-se em Ricoeur (1994), entende-se por narrativa uma configuração de acontecimentos individuais em uma história, a construção de uma totalidade inteligível. Os temas mais recorrentes das narrativas foram futebol, amizade, férias e viagens. Segue o exemplo de uma produção escrita considerada narrativa:

Participante 2 - Post 4 Título: Férias

Eu viaja na Bauru, meu primo fala muito saudade para meu irmão. Meu irmão fica na Campinas, porque ele tem um última aula. Sábado manhã viaja Guarulhos. Depois tarde volta na Vacaria.

Domingo volta para na Campinas, junto tia e o tio com carro. Eu fala o que anteceu fez na Bauru. Última semana volta escola. Eu gosta denovo férias, porque muito bom férias, mas gosta pouco escola precisa mais aprender aula. Meu irmão quer pouco brinca mim. Eu não quer mais brinca para ele.

Amigas falam o que antecem às férias, mas todos alunos não gostam na escola. Amigas muito saudade todos.

Apesar das dificuldades na construção gramatical, é possível notar que há uma história tecida através do encadeamento de ações que remetem ao tema férias. Observa-se que os diferentes marcadores temporais ("sábado manhã", "depois tarde", "domingo", "ultima semana") expressam momentos distintos, explicitando a passagem do tempo e permitindo a construção de uma história. A narrativa apresenta uma estrutura temporal convencional, na qual o encadeamento das ações corresponde à ordem cronológica dos acontecimentos: a narrativa inicia no passado até o desfecho em um passado mais recente, ou seja, do início das férias até o começo das aulas.

Não foram consideradas como narrativa as produções escritas que se limitavam a descrições. A produção abaixo acompanhava uma figura de um carro de corrida em uma estrada de chão:

Participante 1 - Post 5 Título: Corrida

Uma foto para carro, lugar a país qualquer mais longe era fazer uma carro rapidamente muita pó a território, muitas bonitas das florestas o grande rio demais de limpa.

Nesse post, o autor limita-se a descrever os elementos presentes na imagem: um carro que passa velozmente por uma estrada de terra, um rio e a floresta. Não há elementos temporais que permitam indagar sobre a questão "e depois?", ou seja, sobre os elementos narrativos que se encadeiam na tessitura da narrativa como o antes e o depois do "carro passar" ("e depois" é uma expressão utilizada por Ricoeur (1994) para indicar a relação de exterioridade entre as ações; é o encadeamento das ações em narrativa que permite ao leitor perguntar-se sobre o depois de cada ação). 
Nota-se que as produções escritas, em geral, restringiram-se a narrar ações e circunstâncias de forma simples. Isso pode ser explicado pela dificuldade de expressão desses adolescentes surdos no português escrito. O post seguinte exemplifica a dificuldade em superar a linearidade das ações:

Participante 2 - Post 1 Título: Basquete

Grupos alunos gostam muitos só basquete. Ontem eles foi na universidade, porque jogo outros alunos. Difícil sentimento não tem jeito. Alunos sempre treino basquete. Já treino basquete três anos. Outros alunos pequeno idade continue treino basquete.

A frase "Difícil sentimento não tem jeito" é um elemento de reflexão, em que parece haver a tentativa de exprimir um sentimento, algo mais complexo que uma simples ação. No entanto, a frase não chega a transmitir um sentido claro, passível de ser interpretado sem realizar muitas inferências.

A segunda etapa da análise visou identificar os personagens, interações, ações e circunstâncias de cada narrativa. O personagem só pode ser apreendido em relação à ação (Ricoeur, 1994). Por isso, mantiveram-se esses três elementos como pertencentes a uma mesma categoria de análise. Essas narrativas autobiográficas têm como personagens os próprios autores (eu), pais, irmãos, amigos surdos e ouvintes, outros parentes (tia, tio, primo, avós) e colegas de aula. Também aparecem seleções de futebol (Brasil, Argentina e Alemanha) e Ronaldinho Gaúcho.

O personagem pode ser apresentado de modo ativo, situação na qual ele realiza a ação, bem como de modo passivo, em que sofre a ação. Em geral, o personagem "eu" dessas narrativas aparece como ativo. Na narrativa a seguir, o autor torce pela seleção do Brasil e projeta ações no futuro, mostrando-se ativo:

Participante 1 - Post 1 Título: Futebol

Eu o muito gosta dia-dia a joga o televisão a Copa do Brasil, eu forte gol oBrasil mais as muitas gollll, Copa do Mundial luta a mais golll! o campeão o Brasil, eu vou ver o televisão Copa do Mundial a anos : 2006.

Eu tem o dentro amor do "Brasil". Eu o que fez

$\mathrm{Na}$ narrativa autobiográfica, o autor-narrador-personagem pode construir diversas versões sobre si mesmo e ressignificar sua existência. A análise dos personagens e interações também permite visualizar a ocorrência ou não de transformações de si na narrativa. No post 4 da participante 2, pôde-se observar que a autora sofre inicialmente a ação ("Meu irmão quer pouco brinca mim") mas, em seguida, ocorre uma transformação da personagem ("Eu não quer mais brinca para ele").

No post a seguir, observa-se outra transformação no curso da narrativa:

Participante 2 - Post 3 Título: As amigas

Eu tenho poucos as amigas. Eu tem uma amiga verdade muitos anos, amiga vizinha minha casa. Sempre domingo entre e saída casa de amiga. Eu foi à escola encontre as amigas conversam os gurpos. Amiga sempre fala adoro RAP, ela todo dias viu na televisão de RAP. Os grupos gostam muitos bobagem.

Eu gosta muitas amigas muito carinho, alegria e legal. Meu tinha um irmão sempre brinca com primo segundo. Aquela amiga fala comigo, RAP muito bom mensagem, agora entender.

Nota-se que há uma constância: "amizade verdade muitos anos". Ao mesmo tempo, a escola é um marco da transformação, pois quando a autora começa a frequentá-la, ela passa a ter mais amigas ("encontre as amigas conversam os gurpos"). Outra transformação pode ser vista ocorrendo no tempo presente, quando a amiga fala sobre a música rap ("muito bom mensagem, agora entender").

As interações caracterizam-se por laços afetivos como nos seguintes exemplos: "saudade" (Participante 2, post 4); "carinho", "alegria" e "legal” (Participante 2, post 3); e "amizade" (Participante 1, post 3; Participante 2, post 3). As descrições das circunstâncias onde as ações aconteceram constituem cenários como casa, escola, viagens, cidades, universidade, danceteria. Em sua maioria, as narrativas são alegres e trazem elementos positivos da vida familiar ou escolar:

Participante 1 - Post 3 Título: Férias

Meu irmão o junto a cidade em Campinas, vem o tio para a casa o depois o papo da família: primo (a), meu irmão visita a amizade a para em casa, uma semana de férias, depois eu foi vem a agora aqui em Bauru, sempre a escola os amigos dos surdos papo piada.

A terceira etapa da análise constituiu-se na identificação das mediações simbólicas (regras, normas, julgamentos) e das relações entre o narrador e seu leitor, elementos relativos às mimeses I e III. Ou seja, a ênfase da análise está no universo simbólico em que estes jovens estão inseridos.

As relações entre surdos e ouvintes têm implicações sobre as percepções de si mesmo e as construções identitárias do surdo. As narrativas dos três adolescentes surdos indicam que eles mantêm relações importantes com pessoas ouvintes, em especial familiares e amigos. No post 4 da participante 2, por exemplo, ela descreve interações com o primo que é ouvinte: "meu primo fala muito saudade para meu irmão" e, posteriormente, "Eu fala o que anteceu fez na Bauru".

No post 3, o participante 1 indica interagir com ouvintes como o irmão, a família e o tio ("vem o tio para a casa o depois o papo da família"), e com surdos como os amigos e a vizinha ("sempre a escola os amigos dos surdos papo piada"). No post a seguir, é possível notar as interações do participante 1 com seus amigos ouvintes:

Participante 1 - Post 4 Título: Amizade

Meu é amizade do muito legal o amigo de nome: Luis e Fernando irmãos a para em São Bernando, dia-dia o jogo 
da game, meu e amizade o junto ir avó a para casa , depois avó a falava de vocês quer a comprar mercado só o quatro da pizzas, Luis a fala quer a comprar do filme? avó o pode de filme, depois meu é amizade a falar ir a casa. - avó a falava pare o pouco do rápidmento deu ter o muito da caxia de bombom, avó a falava venha mim do beijo os vocês. meu é amizade o rápido a pegar avó do beijo a abracão, meu é amizade ir a casa a tchauu? Avó a tchau é fim.

O participante 3 , por sua vez, busca inserir-se no contexto ouvinte. Em sua única produção, ele explicita a relação entre surdos e ouvintes. Ele julga estar com pessoas perigosas, que usam droga, e quer os amigos surdos e ouvintes juntos.

Participante 3 Post 1 Título: Hip hop

porque voce gosto hip hop

Eu sempre muito hip hop

sempre junto amigos com foi dançeteria.

Eu tem pessoa muito junto perigos tem droga.

Eu quero junto muito amigos surdo e ouvinte.

Nas narrativas, notam-se elementos identitários comuns tanto a surdos quanto a ouvintes como jogar basquete e torcer para a seleção brasileira de futebol. Também há referências a elementos que são mais presentes no contexto ouvinte como a danceteria e a música rap. Isso indica que esses adolescentes surdos compartilham elementos identitários comuns a muitos outros adolescentes. O rap e o hip hop, por exemplo, são movimentos que têm implicações além da música, como no comportamento e vestimenta dos jovens. Torcer pela seleção futebol indica uma abertura para a cultura nacional mais ampla, com um forte apelo de identificação:

Participante 1 - Post 2 Título: Futebol

Eu gosto dia-dia o fetubol de televisão, Agora mim ver o campeão o Brasil de goolll. Ontem mim ver televisão o futebol o Brasil 4x1 Argentina, Goolll o Brasil o campeão os grupos das colegas o Brasil a dança a fez o Ronaldinho Gaúcho o pandeiro os muitos de feliz goolll o campeão o Brasil.

Começa a Copa da Mundial o ano 2006. Futebol as muitas as países de região o depois a começa de visita a entrar as países lugar encontrar um a país Alemanha. Meu família a fez a mais goolll o Brasil. Já a final a campeão a Alemanha $x$ Brasil.

Os julgamentos também se constituem em elementos a serem analisados nas mediações simbólicas. No post 4 da participante 2 (ver acima), ela afirma que os alunos não gostam de voltar à escola, diz querer estar em férias de novo. No entanto, ela logo assume um discurso mais maduro, característico dos professores e dos pais ("mas gosta pouco escola precisa mais aprender aula"). No post 3 da mesma autora, há um julgamento de valor ("Os grupos gostam muitos bobagem"). "Bobagem" se constitui num julgamento que opera uma quebra na linearidade das ações narradas.
Quanto às relações entre narrador e leitor, os principais interlocutores eram os próprios colegas e amigos, visto que a estrutura proposta nos blogs incentiva a interação, pois cada autor pode ter a sua lista de contatos. Os amigos são convidados a ler e a responder a cada post. Embora neste momento essas interações não estejam sendo avaliadas, percebe-se a presença implícita do leitor nas narrativas: no post 3, a autora parece narrar para suas amigas ("Eu gosta muitas amigas muito carinho, alegria e legal"). No post 5 , a autora volta a narrar sobre/para as colegas:

Participante 2 - Post 5 Título: Amizade

(...) "Os alunos muitos amigos mais relação, papo, conversar, brincar, esporte e divertar. Nunca briga, fofoca, brabo e separar o amiga".

\section{Discussão}

A análise das narrativas destes adolescentes surdos indicou que, apesar de apresentarem dificuldades na escrita, as produções dos surdos podem construir e transmitir sentido. No entanto, a transmissão do sentido não é bem sucedida em diversos momentos, indicando dificuldades na aprendizagem da estrutura da língua escrita e na compreensão de que a língua escrita pode ser um meio de comunicação com o outro. Estas dificuldades podem estar relacionadas a diferentes fatores que estão envolvidos no processo de alfabetização. Watson (1999) identifica os seguintes critérios para a alfabetização de crianças surdas: uma sólida base linguística, a habilidade de usar essa base linguística para os propósitos da alfabetização, um amplo conhecimento do mundo, dos livros e de histórias e a habilidade de agir sobre as palavras em contexto de leitura e escrita.

Observaram-se diferenças individuais entre esses adolescentes surdos quanto ao grau de proficiência em português. A participante 2, por exemplo, apropria-se melhor dos recursos narrativos e mostra-se capaz de produzir elementos que superam a simples linearidade das ações narradas. A coleta de dados complementares em entrevistas autobiográficas com os adolescentes surdos permite ressaltar a importância do diagnóstico precoce, da construção de uma sólida base linguística e da comunicação entre pais ouvintes e filho surdo (Bremm \& Bisol, 2008). Em pesquisa de Toscano e cols. (2002), estudantes surdos bem sucedidos na leitura e na escrita identificaram que a motivação e a comunicação familiar, o envolvimento dos pais nas atividades do filho surdo e com a comunidade surda desempenharam um papel importante no desenvolvimento das habilidades para ler e escrever. $\mathrm{O}$ envolvimento e suporte foram percebidos pelos estudantes como fatores importantes no seu sucesso. Também, como afirma Silva (1999), as dificuldades dos surdos com a aprendizagem da escrita do português estão relacionadas com a aquisição e desenvolvimento de uma língua efetiva que lhes permita uma identidade social e cultural.

O participante 3, por sua vez, apenas aos três anos teve o diagnóstico de surdez (é importante lembrar que os pri- 
meiros anos de vida são essenciais para o desenvolvimento da linguagem). Além disso, os pais não conseguiram estabelecer formas de comunicação eficientes de modo a possibilitar, por exemplo, que o filho conhecesse histórias da sua vida anteriores aos sete anos. Como foi possível observar em sua narrativa, o adolescente expõe-se a situações de risco como o uso de drogas e busca inserir-se em grupos de ouvintes.

Observou-se uma melhora qualitativa nas produções escritas dos participantes 1 e 2 à medida que começaram a postar com mais frequência. Observando os posts 1 e 4 destes participantes, nota-se que essa melhora consistiu, por vezes, em produções mais extensas, ou em tentativas mais bem sucedidas de narrações no passado, no presente e no futuro, maior número de referências a pessoas e a locais e uso mais frequente de marcadores temporais. Nota-se que esses elementos imprimem maior complexidade à trama narrativa. São observadas diferenças individuais: os surdos que se apropriaram melhor da língua escrita foram os mesmos que, no estudo complementar (Bremm \& Bisol, 2008), produziram narrativas sinalizadas mais ricas.

Durante as sessões em que foram produzidos os blogs e os posts, a língua de sinais operou uma função de mediação e apoio para a produção escrita e para o manuseio do computador e da internet. O blog também permitia trabalhar aspectos estéticos da sua formatação, tornandose atraente para os adolescentes. O ambiente virtual permitiu criar momentos descontraídos de produção em que, ao contrário da sala de aula tradicional, a escrita dirigia-se prioritariamente aos colegas e não aos professores, e podia ser explorada livremente. O estudo da utilização do blog como instrumento para o ensino e aprendizagem da língua escrita, embora incipiente, mostra-se promissor. Acredita-se que possa proporcionar espaços conversacionais motivadores que contribuam para a inserção dos jovens surdos na sociedade do conhecimento.

\section{Considerações finais}

O estudo de narrativas pode trazer avanços para o estudo da escrita dos surdos. Ao invés de enfatizar as dificuldades da escrita, esta abordagem enfatiza a construção do sentido e valoriza a produção do surdo. Apesar dos adolescentes surdos apresentarem graus diferentes de apropriação da habilidade para a escrita, eles motivaram-se com as tarefas propostas e procuraram transmitir algo de sua experiência de vida através da forma escrita, que não é sua forma preferida e mais cômoda de comunicação. Outro elemento interessante que pode ser enfatizado na análise dos dados é a interação entre os adolescentes surdos através da ferramenta de comentários disponível nos blogs, que permitia que os colegas comentassem os posts uns dos outros. Essa ferramenta fortalece a noção (importante de ser desenvolvida com crianças surdas) de que a escrita tem uma função e um significado, constituindo-se em uma possibilidade a mais de comunicação com o mundo e com o outro.
Embora não tenha sido analisado nesse trabalho, notou-se que as trocas comunicativas permitiram que uma rede social digital pudesse se esboçar entre esses estudantes surdos. Esse aspecto pode remeter a situações futuras em relação a grupos constituídos com fins de pesquisa e educação, como o apresentado nesse trabalho, bem como comunidades virtuais espontâneas que surgem na internet, das quais participam autores surdos.

\section{Referências}

Almeida, E. C. (2002/2003). Leitura e Surdez: um estudo com adulto não oralizado. Revista Espaço, 18-19, 1-7.

Arcoverde, R. D. L. (2006). Tecnologias digitais: novo espaço interativo na produção escrita dos surdos. Caderno Cedes, 26(69), 251-267.

Bisol, C. A. (2008). Adolescer no contexto da surdez: questões sobre a sexualidade. Tese de Doutorado, Universidade Federal do Rio Grande do Sul, Porto Alegre, Rio Grande do Sul.

Breivik, J. K. (2005). Deaf identities in the making: local lives, transnational connections. Washington, D.C.: Gaulladet University Press.

Bremm, E. S., \& Bisol, C. A. (2008). Sinalizando a adolescência: narrativas de adolescentes surdos. Psicologia: ciência e profissão, 28(2), 272-287.

Camargo, T., Valentini, C. B., \& Bisol, C. A. (2005). Weblog na educação de surdos. Em: Encontro Nacional de Educação e Informática. Anais do Encontro Nacional de Educação e Informática (CDROM), Caxias do Sul- Rio Grande do Sul.

Capovilla, F. C. \& Capovilla, A. S. (2002). Educação da criança surda: o bilinguismo e o desafio da descontinuidade entre a língua de sinais e a escrita alfabética. Revista Brasileira de Educação Especial, 8(2), 127-156.

Góes, M. C. (1996). Linguagem, surdez e educação. Campinas: Autores Associados.

Guarinello, A. C., Massi, G., \& Berberian, A. P. (2007). Surdez e linguagem escrita: Um estudo de caso. Revista Brasileira de Educação Especial, 13(2), 205-218.

Gutierrez, S. (2003). Projeto Zaptlogs: as tecnologias educacionais informatizadas no trabalho de educadores. Renote, 1(2), 1-19.

Gutierrez, S. (2005). Weblogs e educação: contribuição para a construção de uma teoria. Renote, 3(1), 1-17.

Henderson-Summet, V., Grinter, R. E., Carroll, J., \& Starner, T. (2007). Electronic Communication: Themes from a Case Study of the Deaf Community. INTERACT, Part I, 347-360. 
Iñárritu, A. G. (Diretor), \& Arriaga, G. (Roteirista). (2006). Babel. Estados Unidos/México: Paramount Classics.

Meirelles, V., \& Spinillo, A. G. (2004). Uma análise da coesão textual e da estrutura narrativa em textos escritos por adolescentes surdos. Estudos de Psicologia, 9(1), 131-144.

Nörth, W. (1990). Handbook of Semiotics. Bloomington and Indianapolis: Indiana University Press.

Ohna, S. E. (2004). Deaf in my own way: identity, learning and narratives. Deafness and Educational International, 6(1), 20-38.

Pereira, M. C., \& Karnopp, L. B. (2003). Leitura e surdez. Letras de Hoje, 39(3), 165-177.

Richardson, R. J. (1999). Pesquisa social: métodos e técnicas. São Paulo: Atlas.

Ricoeur, P. (1994). Tempo e narrativa: tomo / (R.L. Ferreira, trad.). Campinas, SP: Papirus. (Trabalho originalmente publicado em 1991)

Ricoeur, P. (1997). Narratividad, fenomenología y hermenêutica (G. Aranzueque, trad.). Em G. Aranzueque (Ed.), Horizontes del relato: lecturas y conversaciones con Paul Ricoeur. Universidad Autónoma de Madrid: Cuaderno Gris.

Rodda, M., \& Eleweke, J. (2000). Theories of literacy development in limited English proficiency deaf people: A review. Deafness and Education International, 2(2), 110-113.

Silva, M. P. M. (1999). A construção de sentidos na escrita do sujeito surdo. Dissertação de Mestrado, Universidade Estadual de Campinas, Campinas, São Paulo.
Silva, M. P. M. (2000). A construção de sentidos na escrita do sujeito surdo. Em Anais da III Conferência de Pesquisa Sócio-cultural, Campinas, São Paulo.

Stumpf, M. R. (2000). Língua de sinais: escrita dos surdos na internet. Em Anais do V Congresso Iberoamericano de Informática Educativa, Viña del Mar, Chile.

Stumpf, M. R. (2005). Aprendizagem de escrita de língua de sinais pelo sistema SignWriting: Línguas de sinais no papel e no computador. Tese de Doutorado, Universidade Federal do Rio Grande do Sul, Porto Alegre, Rio Grande do Sul.

Toscano, R. M., Mckee, B., \& Lepoutre, D. (2002). Success with academic English: Reflections of deaf college students. American Annals of the Deaf, 147(1), 5-23.

Virole, B. (2001). Développement psychologique de l'enfant sourd: moments critiques. Acesso: 16 nov. 2008. Disponível: <www. benoitvirole.com>

Virole, B. (2003). Apports de l'utilisation précoce de la langues de signes à la dynamique des relations familiales. Acesso : 16 nov. 2008. Disponível: <www.benoitvirole.com>

Watson, L. (1999). Literacy and deafness: the challenge continues. Deafness and Education International, 1(2), 96-106.

Webster, A., \& Heineman-Gosschalk, R. (2000). Deaf children's encounters with written texts: contrasts between hearing teachers and deaf adults in supporting reading. Deafness and Education International, 2(1), 26-44.

\section{Sobre os autores}

Cláudia Alquati Bisol (cabisol@ucs.br)

Universidade de Caxias do Sul, Caxias do Sul - RS

Eduardo Scarantti Bremm (bremm07@hotmail.com)

Universidade de Caxias do Sul, Caxias do Sul - RS

Carla Beatris Valentini (cbvalent@ucs.br)

Universidade de Caxias do Sul, Caxias do Sul - RS

\section{Correspondência}

Cláudia Alquati Bisol

Rua Nico Pires, 1186 apto 31-C

95013-310 Caxias do Sul - RS

\section{Agradecimentos}

Universidade de Caxias do Sul e Datasul Medical. Agradecemos a colaboração do bolsista de iniciação científica Tiago Camargo, da psicóloga Aline Mendes e dos alunos e professores que participaram do projeto. 